\title{
A NOTE ON THE BEST CONSTANTS IN SOME HARDY INEQUALITIES
}

\section{L.-E. PERSSON AND S. G. SAMKO}

Abstract. The sharp constants in Hardy type inequalities are known only in a few cases. In this paper we discuss some situations when such sharp constants are known, but also some new sharp constants are derived both in one-dimensional and multi-dimensional cases.

Mathematics subject classification (2010): 26D10, 26D15.

Keywords and phrases: Inequalities, Hardy type inequalities, sharp constants.

\section{REFERENCES}

[1] G. A. BLISS, An Integral Inequality, J. London Math. Soc. S1-5, 1 (1930), 40-46.

[2] J. S. BRADLEY, Hardy inequalities with mixed norms, Canad. Math. Bull. 21 (1978), 405-408.

[3] G. H. HARDY, Notes on a theorem of Hilbert, Math.Z. 6 (1920), 314-317.

[4] G. H. HARDY, Notes on some points in the integral calculus, LX. A. inequality between integrals, Messenger of Math. 54 (1925), 150-156.

[5] G. H. HARDY, Notes on some points in the integral calculus, LXI. further inequalities betwen integrals, Messenger. Math. 57 (1927), 12-16.

[6] V. KoKilashVili, A. MesKhi, AND L.-E. Persson, Weighted norm inequalities for integral transforms with product kernels, Nova Science Publishers, New York, 2010.

[7] A. Kufner, L. Maligranda, And L.-E. Persson, The prehistory of the Hardy inequality, Amer. Math. Monthly 113 (2006), 715-732.

[8] A. Kufner, L. Maligranda, And L.-E. Persson, The Hardy Inequality - About its History and Some Related Results, Pilsen, 2007.

[9] A. Kufner And L.-E. Persson, Weighted inequalities of Hardy type, World Scientific Publishing Co. Inc., River Edge, NJ, 2003.

[10] V. M. Manakov, On the best constant in weighted inequalities for Riemann-Liouville integrals, Bull. London Math. Soc. 24, 5 (1992), 442-448.

[11] B. Muckenhoupt, Hardy's inequality with weights, Studia Math. 44 (1972), 31-38.

[12] L.-E. Persson And N. SAmKo, Inequalities and convexity, Operator Theory: Advances and Applications. Springer Basel AG (Birkhäuser), 241 (2014), 279-306.

[13] G. TAlenti, Osservazioni sopra una classe di disuguaglianze, Rend. Sem. Mat. Fis. 39 (1969), 171185.

[14] G. Tomaselli, A class of inequalities, Boll. Un. Mat. Ital. 4, 2 (1969), 622-631. 